\title{
Comparison of maternal and foetal outcomes between adolescent and adult pregnancies; a descriptive cross sectional study
}

\author{
Dasanayake DLW ${ }^{1}$, Kularathna WGPN ${ }^{2}$ \\ ${ }^{\prime}$ Department of Obstetrics and Gynaecology, Faculty of Medicine, University of Ruhuna, Galle, Sri Lanka. \\ ${ }^{2}$ Department of Nursing, Faculty of Allied Health Sciences, University of Ruhuna, Galle, Sri Lanka.
}

Correspondence: Dr. D LW Dasanayake

e-mail: lanka.dasanayake@yahoo.com

D https://orcid.org/0000-0003-4330-9641

\begin{abstract}
Introduction: Adolescent pregnancy is a global issue and the trend is increasing specially in South East Asia. Pregnancies at a younger age have major maternal and fetal health consequences. The aim of this study was to compare selected maternal and fetal outcomes of adolescent pregnancies with its adult counterpart in a tertiary care center.
\end{abstract}

Methods: A hospital based descriptive study was conducted at Teaching Hospital Mahamodara (THM), Galle. One hundred adolescent mothers (10-19 years) were compared with 100 adult mothers (20-35 years) who had singleton uncomplicated pregnancy. Pre-tested interviewer administered questionnaire was used as the tool to collect data on basic demography, perinatal, maternal outcomes and mode of delivery. Chi-squared test and $\mathrm{t}$-test were used to compare data and presented as proportions, mean (SD), with $95 \% \mathrm{CI}$.

Results: Mean (SD) age at delivery of adolescent and adult mothers were $18(0.2)$ and $27(0.8)$ years respectively. Of the adolescent mothers $16 \%$ were unmarried. More adolescent mothers had anaemia compared to adults $(38 \%$ vs. $32 \%)$, but the difference was not statistically significant $(p=0.37)$. Adolescent mothers had higher pre term delivery rate compared to adult mothers $(23 \% \mathrm{vs.} 15 \%)$ but the difference was not statistically significant $(p=0.18)$. There were no significant differences in birth weight ( 2.77 vs. $2.82 ; p=0.5$ ) rate of admissions to premature baby unit $(6 \%$ vs. $7 \% ; p=0.8)$ and mean APGAR scores $(9.9$ vs $9.8 ; p=0.3)$ between the two groups. A significantly greater proportion of vaginal deliveries were carried out in adolescents compared to adults ( $75 \%$ vs. $55 \% ; p=0.003)$.

Conclusions: Adolescent mothers underwent a significantly larger proportion of vaginal deliveries compared to adults. Though not significant, anaemia and preterm deliveries were higher than in their adult counter-parts. There was no significant difference between the two groups for the selected perinatal outcomes.

Keywords: Adolescent pregnancy, obstetric outcomes, teenage mothers

\section{Introduction}

Adolescent pregnancies are a global problem occurring in high, middle, and low-income countries. It is estimated that about $11 \%$ of births worldwide are due to adolescent mothers aged 15-19 years, and more than $90 \%$ of these births occur in low and middle income countries (1).
Adolescence is the period where structural, functional and psychological development occurs in a girl and prepares her for motherhood (2). According to UNICEF, adolescent period is a vulnerable phase in human development and it represents a transition from childhood to physical and psychological maturity. During this period, adolescents learn and develop their knowledge 
and skills to deal with critical aspects of their health and development (3).

Adolescent pregnancy is a problem in both developed and developing countries. It raises various issues related to human rights. Adolescents are neither physically nor psychologically ready for pregnancy or childbirth. This reproductive event makes them more vulnerable to complications resulting in devastating health consequences. Obstetric risks are often divided in to categories of maternal complications, mode of delivery and its complications and neonatal outcomes. Complications during pregnancy and childbirth are the leading cause of death for 15-19 year-old girls globally (4). It is a health as well as economic burden to a low resource setting country with higher rates of adolescent pregnancies due to its added complications and social impact. During this period, WHO worked with partners to advocate for attention to adolescents, to build the evidence and epidemiologic base for action to develop and test programme support tools, to build capacity, and to pilot initiatives in the small but growing number of countries that recognised the need to address adolescent health.

In Sri Lanka, only a few studies have been conducted to study the obstetric-outcomes in adolescent pregnancies (5-7). In obstetrics unit in Galle $62 \%$ of teenage pregnancies were unplanned mainly due to ignorance of contraception (7). Teenage pregnancies particularly in those below in 17 years of age have increased risk of adverse pregnancy outcomes mainly psychological morbidity (8).

Adolescent pregnancy plays a significant role in maternal and perinatal health. Identification of the problems associated with adolescent pregnancy help to make decisions to improve reproductive health. Being the only obstetric tertiary care centre in the Southern Province of the country Teaching Hospital Mahamodara (THM) cater to a large number of mothers that include adolescent mothers as well. The aim of this study was to identify maternal and fetal outcomes of adolescent and adult pregnancies comparatively by studying the deliveries that took place at THM during a specified time period. The findings of this study could be useful to the national and regional policy makers to take steps to improve the outcome of adolescent pregnancies.

\section{Methods}

A descriptive cross sectional study was carried out in THM, Galle during the period of $13^{\text {th }}$ June 2019 to $28^{\text {th }}$ December 2019 to compare the maternal and fetal outcomes between a selected group of adolescent and adult mothers. Adolescent mothers were selected according to the WHO definition of age ranging from 10 to 19 years (9). Adults were selected from the age group of 20 to 35 years. Participants were recruited from postnatal wards following childbirth. In both groups, postnatal mothers with pre-pregnancy medical comorbidities, multiple gestations and psychiatric illnesses were excluded. Sample size calculation was done allowing 95\% CI with the precision of the estimate of 0.05 and adding $20 \%$ for dropouts (10). According to the final calculation, 200 mothers were needed for the study.

Convenient sampling method was used with the recruitment of consecutive mothers who were admitted to postnatal ward to achieve a total number of 200 mothers with 100 for each group. Data collection was done using pre tested interviewer administered questionnaire by the principal investigator. Bed head tickets and hand held notes were used to retrieve necessary data. The questionnaire consists of four main sections. Part A of the questionnaire consisted of the details regarding basic demographic data of both groups of mothers (age, Body Mass Index (BMI), parity, ethnicity and educational status) Part B was included adverse maternal outcomes; anaemia, Pregnancy Induced Hypertension (PIH) and Gestational Diabetes Mellitus (GDM). Part C included selected perinatal outcomes; Pre Term Delivery (PTD), Birth Weight (BW), admission to premature baby unit (PBU) and APGAR score and part D included the mode of delivery (VD) and Caesarean section.

Data were analysed using the Statistical Package of Social Science version 25 (SPSS). Numerical variables were analysed using independent t-test and categorical data were analysed using chisquared test. Results of the study were compared and presented as proportions and means with $95 \%$ CI.

The ethical approval was obtained from the Ethics Review Committee, Faculty of Allied Health Sciences, University of Ruhuna before the 
commencement of the study. Informed written consent was obtained from all participants prior to data collection. Inclusion of the eligible participants was done entirely on voluntary basis.

\section{Results}

A total of 200 postnatal mothers were included in the study; 100 adolescents and 100 adults. The response rate was $100 \%$.

The mean (SD) age of adolescents and adults were $18.4(0.2)$ and $27.6(0.8)$ years respectively. There was no significant difference in the mean Period of Gestation (POG) at delivery between adolescent and adult mothers ( 37.8 vs. 38.0 weeks $p=0.7$ ). Adult mothers had significantly higher BMI than adolescents $\left(23.1\right.$ vs. $\left.20.3 \mathrm{~kg} / \mathrm{m}^{2}, p=<0.001\right)$ at booking visit. Adolescent group was significantly less educated than adult group $(p<0.001)$. All adult women were married while $16 \%$ in adolescent group were unmarried $(p<0.001)$. Majority were
Sinhalese in both adolescent and adult mothers (78\% vs. $89 \%)$.and there was a higher proportion of Muslim mothers in adolescent group than in the adult group (16\% vs. $8 \%$ ) (Table 1$)$.

Table 2 demonstrates presence of the selected maternal outcomes in the participants. No statistically significant difference was observed between the two groups with regards to aneamia, while numbers with PIH and GDM were low.

Table 03 summarizes perinatal outcomes of study participants. Rate of PTD was higher among adolescents when compared to adult mothers (23\% vs. $15 \%)$. But this was not statistically significant $(p=0.2)$. There were no statistically significant differences in other perinatal outcome variables such as: BW, admission to PBU and APGAR score at $10 \mathrm{~min}$.

Table 04 shows mode of deliveries among participants. The number of women delivered by vaginally was significantly higher in adolescent group compared to adults.

Table: Socio-demographic characteristics of study participants

\begin{tabular}{|c|c|c|c|c|c|c|c|}
\hline \multirow{2}{*}{$\begin{array}{l}\text { Maternal Characteristics } \\
\text { POG at delivery (days) } \\
\text { Mean } \pm \text { SD }\end{array}$} & \multicolumn{2}{|c|}{$\begin{array}{c}\begin{array}{c}\text { Adolescents } \\
\mathbf{n}=\mathbf{1 0 0}\end{array} \\
\end{array}$} & \multicolumn{2}{|c|}{$\begin{array}{l}\text { Adults } \\
\mathrm{n}=100\end{array}$} & \multirow{2}{*}{$\frac{\chi^{2 *} / t^{* *}}{0.3(t)}$} & \multirow{2}{*}{$\frac{\mathbf{9 5 \%} \text { CI }}{(-0.9)-(-0.6)}$} & \multirow{2}{*}{$\frac{p \text {-value }}{0.7}$} \\
\hline & 37.8 & $( \pm 7.6)$ & 38.0 & $( \pm 8.6)$ & & & \\
\hline $\begin{array}{l}\text { Age at delivery (years) } \\
\text { Mean } \pm \text { SD }\end{array}$ & 18.4 & $( \pm 0.2)$ & 27.57 & $( \pm 0.8)$ & $-21.8(\mathrm{t})$ & $(-10.0)-(-8.4)$ & $<0.001$ \\
\hline $\begin{array}{l}\text { BMI at booking visit }\left(\mathrm{kg} / \mathrm{m}^{2}\right) \\
\text { Mean } \pm \text { SD }\end{array}$ & 20.3 & $( \pm 0.6)$ & 23.14 & $( \pm 1.0)$ & $-4.5(\mathrm{t})$ & $(-4.1)-(-1.6)$ & $<0.001$ \\
\hline \multicolumn{8}{|l|}{ Parity } \\
\hline 1 & 94 & $(94 \%)$ & 42 & $(42 \%)$ & $62.1\left(\chi^{2}\right)$ & $8.7-54.0$ & $<0.001$ \\
\hline$>2$ & 6 & $(6 \%)$ & 58 & $(58 \%)$ & - & - & - \\
\hline \multicolumn{8}{|l|}{ Marital status } \\
\hline Married & 84 & $(84 \%)$ & 100 & $(100 \%)$ & $17.4\left(\chi^{2}\right)$ & $0.4-0.4$ & $<0.001$ \\
\hline Unmarried & 16 & $(16 \%)$ & 0 & $(0 \%)$ & - & - & - \\
\hline \multicolumn{8}{|l|}{ Educational level } \\
\hline$\leq \mathrm{O} / \mathrm{L}$ & 95 & $(95 \%)$ & 52 & $(52 \%)$ & $47.7\left(\chi^{2}\right)$ & $6.6-46.8$ & $<0.001$ \\
\hline$\leq \mathrm{A} / \mathrm{L}$ & 5 & $(5 \%)$ & 48 & $(48 \%)$ & - & - & - \\
\hline \multicolumn{8}{|l|}{ Ethnicity } \\
\hline Sinhala & 78 & $(78 \%)$ & 89 & $(89 \%)$ & $5.4\left(\chi^{2}\right)$ & $(0.2)-(0.9)$ & 0.02 \\
\hline Others & 22 & $(22 \%)$ & 11 & $(11 \%)$ & $5.4\left(\chi^{2}\right)$ & $(0.2)-(0.9)$ & 0.02 \\
\hline
\end{tabular}

POG - Period of gestation

* Chi-squared test $\quad * *$ Independent sample t-test 
Table 2: Maternal obstetric outcomes of study participants

\begin{tabular}{|c|c|c|c|c|c|}
\hline Maternal Outcomes & $\begin{array}{c}\text { Adolescents } \\
(\mathrm{n}=\mathbf{1 0 0})\end{array}$ & $\begin{array}{c}\text { Adults } \\
(n=100)\end{array}$ & $\chi^{2}$ & $95 \%$ CI & $p$-value \\
\hline Anaemia & $38 \quad(38 \%)$ & $32(32 \%)$ & -0.9 & $-0.2-(0.1)$ & 0.4 \\
\hline PIH & $3 \quad(3 \%)$ & $6(6 \%)$ & - & - & - \\
\hline GDM & $3 \quad(3 \%)$ & $9(9 \%)$ & - & - & - \\
\hline
\end{tabular}

Table 3: Perinatal outcomes of study participants

\begin{tabular}{|c|c|c|c|c|c|c|c|}
\hline Perinatal outcomes & $\begin{array}{r}\text { Adol } \\
(\mathbf{n}=\end{array}$ & $\begin{array}{l}\text { escents } \\
=100)\end{array}$ & & $\begin{array}{l}\text { ults } \\
100)\end{array}$ & $\chi^{2 *} / t * *$ & $95 \%$ CI & $p$-value \\
\hline PTD ( $<37$ weeks $)$ & 23 & $(23 \%)$ & 15 & $(15 \%)$ & $2.9\left(\chi^{2}\right)$ & $1.7-1.8$ & 0.2 \\
\hline $\begin{array}{l}\text { Birth weight (kg) } \\
\text { Mean } \_ \text {SD }\end{array}$ & 2.8 & $(0.5)$ & 2.8 & $(0.7)$ & $0.5 \quad(t)$ & $(-208.8)-(117.98)$ & 0.5 \\
\hline Admission to $\mathrm{PBU}$ & 6 & $(6 \%)$ & 7 & $(7 \%)$ & $0.1\left(\chi^{2}\right)$ & $(0.3)-(2.6)$ & 0.8 \\
\hline $\begin{array}{l}\text { APGAR score at } 10 \mathrm{~min} \\
\text { Mean+SD }\end{array}$ & 9.9 & $(0.3)$ & 9.8 & (1.4) & $1.1(\mathrm{t})$ & $(-0.1)-(0.4)$ & 0.3 \\
\hline
\end{tabular}

Table 4: Mode of deliveries among participants

\begin{tabular}{|c|c|c|c|c|c|}
\hline Mode of deliveries & $\begin{array}{c}\text { Adolescents } \\
\mathbf{n}=\mathbf{1 0 0}\end{array}$ & $\begin{array}{l}\text { Adults } \\
\mathrm{n}=100\end{array}$ & $\chi^{2 *}$ value & $95 \%$ CI & $p$-value \\
\hline Vaginal delivery & $75 \quad(75 \%)$ & $55 \quad(55 \%)$ & 8.791 & $1.3-4.5$ & 0.003 \\
\hline $\operatorname{LSCS}^{* *}$ & $25 \quad(25 \%)$ & $45 \quad(45 \%)$ & 8.8 & $0.2-0.7$ & 0.003 \\
\hline
\end{tabular}

* Chi-squared test $\quad * *$ LSCS - Lower segment caesarian section

\section{Discussion}

Adolescent pregnancy and motherhood have remained a major health and social issue as it is associated with adverse consequences to the health of the mother and the child in short and long term basis to a country. Teenage mothers are also likely to suffer from severe complications during pregnancy, child birth and postnatal life, which can be detrimental to both mother and child.
Sri Lanka has achieved substantial improvements in maternal and child health compared to regional countries. WHO recognized that despite low resources, Sri Lanka has highest achievement in teenage pregnancy care in their "Adolescent Pregnancy in South East Asia" report (11). Yet, Sri Lanka has much room to optimize outcomes of adolescent pregnancy with different strategies. 
The study found that adolescent mothers were more likely to have vaginal delivery and had more of them affected with PTD and anaemia than in their adult counter-parts even though the differences were not significant. But there was not much difference between them and adults when we looked into selected perinatal outcomes such as APGAR score and number of PBU admissions of their newborns.

Current study reported higher rate of anaemia among adolescent group compared to adults (38\% vs. $32 \%$ ) even although this is not statistically significant. A study done by Goonewardene, et al., in 2005 in the same setting found that those below 17 years of age had a significantly higher risk of having anaemia compared to controls (6). Nutritional anaemia predominantly due to iron deficiency is the commonest prenatal complication observed in teenagers even in the UK (12). Neuro-developmental delay in younger generation is the most alarming long term consequence due to iron deficiency during pregnancy. This could be prevented with recognition of high risk group such as teenage mothers and implementation of effective strategies such as early booking visit, screening for anaemia and supervised iron supplementation.

In this study, development of PIH was not significantly different between adolescent mothers and adult group, and this finding is consistent with the study done by Kayastha, et al., in 2012 (13). In their study they have found that incidence of hypertensive disorders was not statically significant between adolescent and adult groups. However, some studies reported controversial findings to current study $(14,15)$. In those, a significantly higher risk of PIH in adolescents was reported compared to adults. This difference could be explained with diversity of occurrence of PIH in different geographic locations and methodological differences in above studies. This clearly shows that need of large multicenter study to find out whether there are differences for the incidence of PIH between the two groups of mothers.

We also examined the presence of GDM during pregnancy in adolescents and older mothers. The study failed to show any statistically significant difference in presence of GDM in two groups. But, the incidence of GDM were three times higher in pregnant adults than pregnant adolescents.
A study done by Kositworakitkun, et al., 2016 found that teenage pregnancies had lower rate of GDM than adult pregnancies (16). This could be explained by the risk of occurrence of diabetes in advance maternal age in general population compared to young women.

Management of preterm birth is a challenge in low resource setting such as in Sri Lanka. Current study found that a higher percentage of adolescents had PTD than their adult counterparts even though the difference is not statistically significant. Similar findings were found in a study conducted in Pakistan (14). Another study done in the same setting in 2005 showed that younger teenagers had higher risk of preterm delivery than older teenagers (6). The current study also found that there were no significant differences in other perinatal outcomes such as PBU admissions and APGAR score at 10 min in both groups. Similar finding was reported by Al-Haddabi, et al., in 2014 (17). On the other hand, Aung, et al., in 2017 found that adolescent mothers had significantly higher percentage of babies with poor APGAR score (10\% vs. $3 \%$ ) than adult mothers. These differences may be due to heterogeneity of studies.

This study found that vaginal delivery rate is higher in adolescent mothers than in adult mothers $(75 \%$ vs. 55\%) and on the other hand, cesarean section rate was higher in adult mothers than adolescent mothers $(45 \%$ vs. $25 \%)$. Reviewing previous studies, there were conflicting results regarding mode of delivery. Naz U in 2014 found similar result in line with our study (18). However, different results were described by Sarwar \& Iftikhar in 2016 (14).

There were some limitations of this study. Sample size was too small to find out real difference between groups with regards to some important maternal and perinatal outcomes due to lack of power of study. This study did not examine the other significant parameters of interest such as occurrence of perineal tears, postpartum haemorrhage and maternal psychological morbidity. Choosing adult women would have led to selection bias as they are having higher likelihood of developing medical co-morbidities such as diabetes and hypertension due to advanced maternal age. This could have overestimated the proportion with these diseases 
of the adult group. The recruitment of a sample from a tertiary care referral center could have led to over-representation of adult mothers with medical comorbidities assessed in this study.

\section{Conclusions}

The study found that adolescent mothers were more likely to have vaginal delivery compared to their adult counter-parts. When considering the selected perinatal outcomes; PTD was higher among the adolescent mothers, but there were no comparable differences in the numbers with APGAR score and PBU admissions in both groups and the numbers were low. A higher percentage of adolescent mothers had anaemia compared to adult mothers though the difference is not statistically significant.

\section{References}

1. World Health Organization (WHO). WHO Guidelines on Preventing Early Pregnancy and Poor Reproductive Outcome Among Adolescents in Developing Countries. Geneva: WHO; 2011.

2. Nair A, Devi S. Obstetric outcome of teenage pregnancy in comparison with of 20-29 years: A retrospective study. International Journal of Reproduction, Contraception, Obstetrics and Gynaecology, 2015; 5: 1319-1323.

3. UNICEF: Adolescent Health 2017.

4. Neal S, Matthews Z, Frost M, et al. Childbearing in adolescents aged 12-15 years in low resource countries: A neglected issue. New estimates from demographic and household surveys in 42 countries. Acta Obstet Gynecol Scand, 2012;91: 1114-1118.

5. Ekanayake CD, Tennakoon SUB, Hemapriya S. Teenage Pregnancies: Obstetric Outcomes and their Socio Economic Determinants a Descriptive Study at Teaching Hospital Kandy. Sri Lanka Journal of Obstetrics and Gynaecology, 2016;37(3): 47-53.

6. Goonewardene IMR, Waduge RPKD. Adverse effects of teenage pregnancy. Ceylon Medical Journal, 2005; 50(3): 116-120.

7. Gunaratne KA, Goonewardene Malik. Teenage pregnancy and contraception. Sri Lanka Journal of Obstetrics \& Gynaecology, 2001;23: 9-15.
8. Goonewardene Malik. Teenage pregnancy. Sri Lanka College of Obstetrics \& Gynaecology 2001; 23: 4-11.

9. WHO. 2004. Adolescent Pregnancy: Issues in Adolescent Health and Development. [Online] Available at: https://www.who.int/maternal_child_adolescent/ documents/9241593784/en/ [Accessed 15 February 2020].

10. Aung SH. A retrospective study of maternal and fetal outcome of adolescent pregnancy in Kawthaung province, Myanmar. Bangladesh Journal of Medical Science, 2017; 16(4): 535-540.

11. World Health Organization. Adolescent Pregnancy Situation in South- East Asia Region. Available from: http://apps.searo.who.int/PDS_DOCS/B5164.pdf. Published 2014. [Accessed on August 20, 2020].

12. Konje JC, Palmer A, Watson A, Hay DM, Imrie A. Early teenage pregnancies in Hull. British Journal of Obstetrics \& Gynaecology, 1992; 99: 969-973.

13. Kayastha S, Pradhan A. Obstetric Outcome of Teenage Pregnancy. Nepal Journal of Obstetrics and Gynaecology, 2012; 7(2): 29-32.

14. Sarwar A, Iftikhar T. Comparative Study of Obstetrical Outcomes of Teenager and Older Primigravida. Annals of PIMS, 2016; 12(2): 82-85.

15. Ganchimeg T, Ota T, Morisaki N, et al. Pregnancy and childbirth outcomes among adolescent mothers: A world Health Organization multi country study. BJOG, 2014; 121(1): 40-48.

16. Kositworakitkun L, Watcharoton W, Junalpakee C. Comparison of Maternal and Neonatal Outcomes of Teenage versus Adult Pregnancies at Buddhachinaraj Hospital. The Journal of Obstetrics and Gynaecology, 2016; 24(3): 169-174.

17. Al-Haddabi M, Al-Bash M, Al-Mabaihsi N, Al-Maqbali N, Al-Dhughaishi T, Abu-Heja A. Obstetrics and Perinatal Outcomes of Teenage Pregnant Women Attending a Tertiary Teaching Hospital in Oman. Oman Medical Journal, 2014; 29(6): 399-403.

18. Naz U. Comparison of Obstetric Outcome in Terms of the Risk of Low Birth Weight, Preterm Delivery, Cesarean Section Rate and Anaemia in Primigravida Adolescents and Older Primigravida. Journal of the College of Physicians and Surgeons Pakistan, 2014; 24(2): 131-134. 